Global Proceedings Repository

American Research Foundation

ISSN 2476-017X

Available online at http://proceedings.sriweb.org

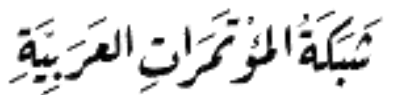

http://arab.kmshare.net/

The 1st International Conference on Sciences and Arts (ICMSA 2017)

$$
\begin{aligned}
& \text { المؤتمر الدولي الاول للعلوم والاداب } \\
& \text { مايو } 2017 \text { - اربيل - العراق3 }
\end{aligned}
$$

\title{
Highly Stable Gold NanoparticlesusingGel as Reducing Agent and Stability: evaluation of its free radical scavenging activity
}

\author{
Rana M. Yas ${ }^{\mathrm{a}}$, Muna Ahmed Saeed ${ }^{\mathrm{a}}$,Dhelal Abdul Ghafoor ${ }^{\mathrm{b}}$ \\ ${ }^{\text {a }}$ Department of Physics, College of Science, University of Baghdad, Iraq. \\ ${ }^{b}$ Department of Chemistry, College of Science, University of Anbar, Iraq.
}

\begin{abstract}
The research was focused on the production, characterization and application of Gold nanoparticles $\left(\mathrm{AuNP}_{\mathrm{s}}\right)$, which can be utilized in biomedical research and environmental cleaning applications.In vitro free radical scavenging activity of synthesized gold nanoparticles (AuNPs) was investigated. There are many studies use chemical method to synthesis gold nanoparticles (AuNPs) using various chemicals do as reducing agents at different conditions. In this study, gold nanoparticles (AuNPs )were synthesized by gel as reducing and stabilizing agent to reduce $\mathrm{Au}^{+3}$ ions form chloroauric acid $\left(\mathrm{HAuCl}_{4} \cdot 3 \mathrm{H}_{2} \mathrm{O}\right)$ to nano gold .The reactionwere required heating around $60-80{ }^{\circ} \mathrm{C}$. Synthesis of colloidal Au NPs was monitored by UV-Visible spectroscopy. The UV-Visible spectrum showed $524 \mathrm{~nm}$, The characterization of the AuNPs such as their size, shape and stabile was performed by zeta potential , Atomic Force Microscopy (AFM), Transmission Electron Microscopy (TEM) techniques which indicated a size range of 14 to $25 \mathrm{~nm}$. The in vitroantioxidant properties of AuNPs using DPPH assay have been evaluated and these nanoparticles were found to have
\end{abstract}




\section{Global Proceedings Repository \\ American Research Foundation}

ISSN 2476-017X

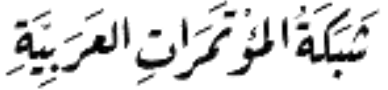

http://arab.kmshare.net/

Available online at http://proceedings.sriweb.org

higher antioxidant capacity and thus can be used as potential radical scavenger against deleterious damages caused by the free radicals.

Key words: Gold nanoparticle ,gel, characterization, synthesis, stabilizing,in vitro DPPH assay,free radicals scavenger.

\section{Introduction:}

Metallic nanoparticles (NP) are attracting attention of chemist due to their novel properties including high surface area and exceptional surface activity. ${ }^{\mathbf{1}, 2}$ Several physical and chemical methods have been employed in the preparation of AuNPs. Chemical reduction, for instance, the Turkevich route is still considered one of the most applied procedures in the synthesis of AuNPs.Reduction of $\left(\mathrm{Au}^{+3}\right)$ ions using sodium citrate in hot aqueous solution gives gold metal $\left(\mathrm{Au}^{0}\right)$ colloid. AuNPsare prepared by chemical reduction, typically performed by reducing $\mathrm{HAuCl}_{4}$ in aqueous solutions. ${ }^{(3)}$ In this work. Commercial and laboratory gel is used as reducing and stabilizing agentgel preparation has remains one of the most popular and important pharmaceutical dosage forms. The formulation of an effective gel requires the use of an appropriate gelling agent, usually a polymer. The preferred characteristics of such polymer include the inertness, safety, and biocompatibility with other ingredients, good adhesion to mucous membrane, and permission of drug permeation while not being absorbed into the body. When in the formulation, the polymer should exhibit good swelling, syneresis and rheological properties suitable for solidifying stiffening the system. A number of gelling agents have been commercially employed in the preparation of gel, including the synthetic carbomers and the semi-synthetic cellulose, cellulose derivatives. ${ }^{(\mathbf{4 , 5 , 6 )}}$ Caropol is made of carbomers. Carbomerpolymers are cross-linked together andmake a microgel structure that makes them optimal to be used as a drug vehicle fordermatological purposes. They can be used in cases when drug delivery in acontrolled manner is desired. Carbopol polymers are acrylic acid cross-linked with polyalkenyl ethers or divinylglycol. These polymers are anionic polymers that need naturalization to become gellified. Organic amines like triethylamine can be used to naturalize these polymers in liquids. Carbopol polymers have been used in the personal care industry for forty years. They have been used in producing gels, creams, lotions and suntan products. Carbopol gels have been applied as drug vehicles inseveral routes of administration. ${ }^{(\mathbf{7 , 8 , 9 )}}$

Ionizing radiation is a form of energy travelling either as electromagnetic waves ( $\mathrm{x}$-rays and gamma rays) or particles (alpha, beta, neutrons etc). They transmit energy to materials they encounter. Faster or heavier particles deliver a harder punch. ${ }^{(10)}$

Ionizing radiation causes damage to living system through a series of molecular events, such as Photoelectric, Compton and Auger effects, depending on the radiation energy. Since the predominant molecule in biological systems is water, it is usually the intermediary of the radical formation and propagation. The major radiation damage is due to the aqueous free radicals, generated by the action of radiation on water.A free radical is an electrically neutral atom with an unshared electron in the orbital position, where the radical is highly reactive. ${ }^{(\mathbf{1 1})}$ They can either donate an electron to or accept an electron from other molecules, therefore behaving as oxidants or reductants. ${ }^{(\mathbf{1 2})}$ An antioxidant may terminate the oxidative 


\section{Global Proceedings Repository \\ American Research Foundation}

ISSN 2476-017X

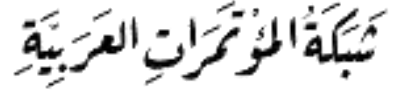

http://arab.kmshare.net/

Available online at http://proceedings.sriweb.org

potentiality by scavenging the free radical which is generated during oxidation process. To date, large number of natural and synthetic antioxidants has been investigated to inhibit these oxidation reactions.

Recently, some progresses have been achieved in the evaluation of antioxidant activity of nano materials, due to the physicochemical and optoelectronic properties ${ }^{(13,14)}$ Among various metal nanoparticles, AuNPs are well-suited for a wide range of biological applications because of its chemical inertness and resistance to surface oxidation. ${ }^{(15,16)}$

DPPH (2,2-diphenyl-1-picryl-hydrazyl-hydrate) free radical method is an antioxidant assay based on electron-transfer that produces a violet solution in ethanol. This free radical, stable at room temperature, is reduced in the presence of an antioxidant molecule, giving rise to colorless ethanol solution. The use of the DPPH assay provides an easy and rapid way to evaluate antioxidants by spectrophotometry, so it can be useful to assess various products at a time.The antioxidant effect is proportional to the disappearance of DPPH in test samples. Monitoring DPPH with a UV spectrometer has become the most commonly used method because of its simplicity and accuracy. DPPH showed a strong absorption maximum at 517 nm (purple). ${ }^{(17)}$

The aim of the present work is the synthesis of colloidal Au NPs by gel as reducing and stabilizing

agent to reduce $\mathrm{Au}^{+3}$ ions form chloroauric acid $\left(\mathrm{HAuCl}_{4} \cdot 3 \mathrm{H}_{2} \mathrm{O}\right)$ to nano gold. Depending on the results, AuNPswere used as free radicalsscavengers in water samples due to ionizing radiation.

\section{Experimental Section:}

\section{Chemicals}

Research chemicals were supplied by HIMEDIA company-India and MERCK CompanyGermany. DPPH were purchased from Sigma Aldrich by United Tetra Group for Medical and Scientific Supplies / Jordan.

Water samples were irradiated by $137 \mathrm{Cs}$ gamma source. The synthesized colloidal gold nanoparticles were used with a series of concentrations $(53.7,107,134.3,159.3,214.8,242.65$ $\mu \mathrm{g} / \mathrm{ml}$ ) which were determined by atomic absorption method.

\section{Instruments}

UV-Vis spectroscopy (Shimadzu, Japan), Atomic force microscope (AFM); (SPM AA 3000, USA); Transmission electron microscope (TEM); (Philips CM 100, Holland), and Zeta potential analyzer (Brook haven, USA) are used for the characterization of AuNPs.

\section{Preparation of Aqueous Gold Nanoparticles:}

$5 \mathrm{gm}$ of gel was dissolved in $250 \mathrm{ml}$ distilled water and the solution was heated up to the range $60-70$ 0C. To this mixture $3.6 \mathrm{~mL}$ of $10 \mathrm{mM}$ HAuCl4.3H2O (99\%, HIMEDIA, India) were added drop wise with continues stirring. After 20 minutes the color of the solution was changed from pale yellow to ruby-red color, indicating the formation of AuNPs.

\section{Characterization of Gold Nanoparticles:}




\section{Global Proceedings Repository \\ American Research Foundation}

ISSN 2476-017X

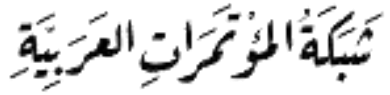

http://arab.kmshare.net/

Available online at http://proceedings.sriweb.org

AuNPswere characterized by UV-Vis spectroscopy (Shimadzu, Japan), Zeta potential analyzer (Brook haven, USA), Atomic force microscope (AFM) - (SPM AA 3000, USA), Transmission electron microscope (TEM), and (Philips CM 100, Holland).

\section{Determination of free radical scavenging activity:}

The free radical scavenging capacity of gold nanoparticles was assayed using the modified DPPH method as reported previously.(18)DPPH (2, 2-diphenyl-1- picrylhydrazyl) is a stable free radical and has been used as a model free radical compound to evaluate the effectiveness of antioxidant. Ethanolic solution of DPPH $(0.1 \mathrm{mM})$ was prepared and incubated at ambient temperature. To prevent free radical formation, AuNPs added to the water samples after irradiation process. Different concentrations (0.0234-0.2681g/l) of AuNPs were added, in equal volume, to ethanolic DPPH solution and water sample. The mixture was shaken vigorously and allowed to stand for $30 \mathrm{~min}$ in the dark and the absorbance of all samples was monitored around $520 \mathrm{~nm}$. DPPH solution without gold nanoparticles served as the control.The percentage inhibition of DPPH was calculated according to the formula:

$\%$ Inhibition $(\mathrm{I} \%)=[(\mathrm{Ac}-\mathrm{As}) / \mathrm{Ac}] \times 100$

whereAc is the absorbance of irradiated water with DPPH radical samples as a control, and As is the absorbance of samples with different concentration of gold nanoparticle.

\section{Results and Discussion:}

AuNPs produced from reduction of gold ions by gel, were characterized by UV-Vis spectra as giving absorption peak at $524 \mathrm{~nm}$. After one year and half give it same absorption peak at $524 \mathrm{~nm}$ that indicatesAuNPS was very stable. This is identical to what has been reported elsewhere .(19)Theoretically, AuNPs absorb visible light between (500-600 nm) due to surface plasmon resonance.

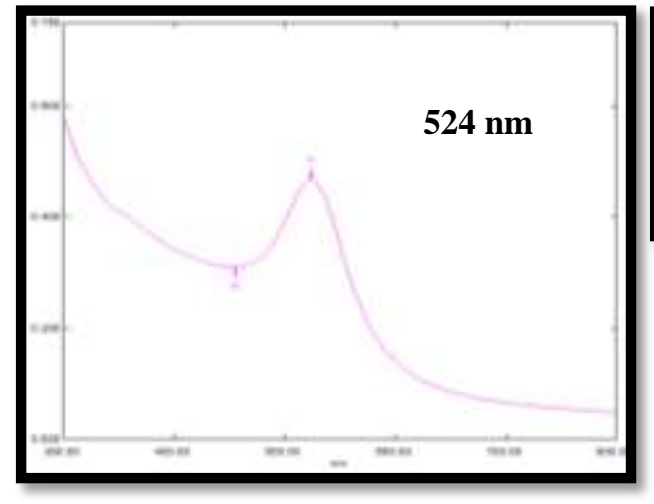

A (before one and half year)

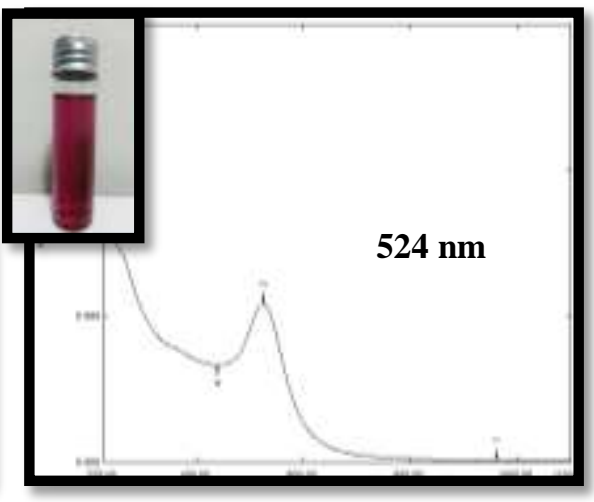

$\mathrm{B}($ after one and half year)

Figure 1: UV-Vis spectra of synthesized AuNPs using gel as reducing agent. 
ISSN 2476-017X

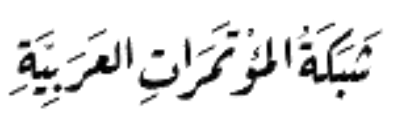

http://arab.kmshare.net/

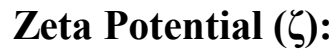

The zeta potential of a colloidal solution is a tool used to measure the stability of such solutions. The colloidal solution is considered to be unstable. If it's recorded zeta potentials were in the range $-30 \mathrm{mV}$ and $+30 \mathrm{mV}$. A high value, positive or negative, of zeta potential means a higher repulsion between the particles. Therefore, colloidal suspensions are considered stable when their zeta potentials are more positive than $+30 \mathrm{mV}$ or more negative than $-30 \mathrm{mV}$.(20)The more negative zeta potential value of our synthesized AuNPs solution ($40 \mathrm{mV}$ ) indicates its stability and coinciding with other works.

\section{Atomic Force Microscopy (AFM):}

The atomic force microscope (AFM) is suited for characterizing nanoparticles. It offers the capability of 3D visualization and both qualitative and quantitative information on many physical properties including size, morphology, surface texture and roughness. Statistical information, including size, surface area, and volume distributions can be determined as well. A wide range of particle sizes can be characterized in the same scan, from 1 nanometer to 8 micrometers. (21)The particle size distribution for the synthesized gold nanoparticles was (70 $\mathrm{nm})$ as show in Figure 2.

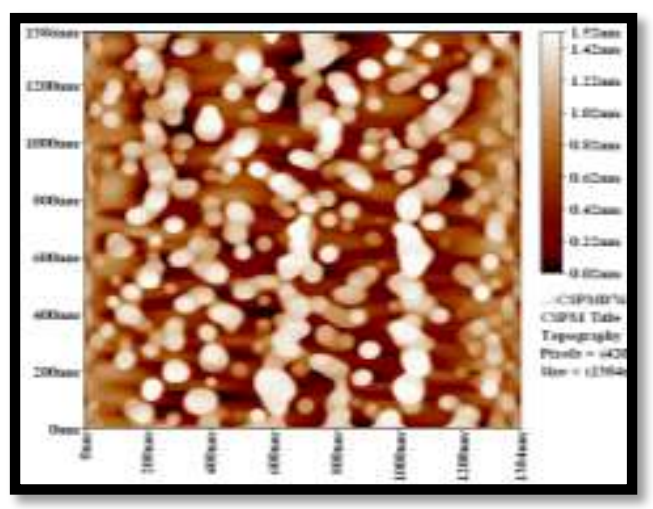

A

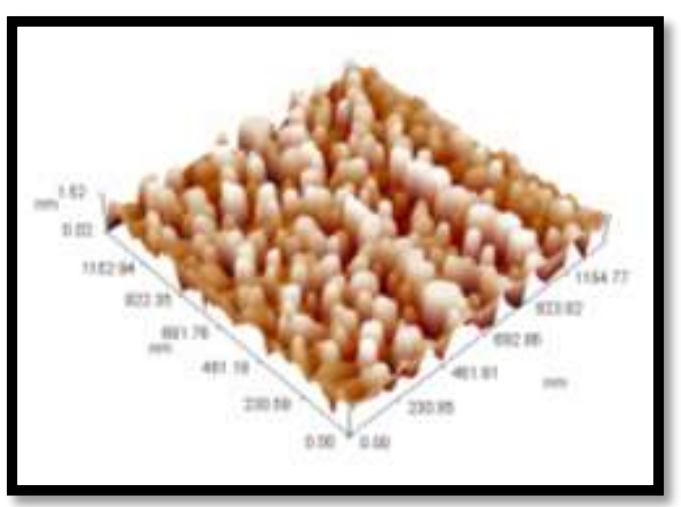

B 


\section{Global Proceedings Repository \\ American Research Foundation}

ISSN 2476-017X

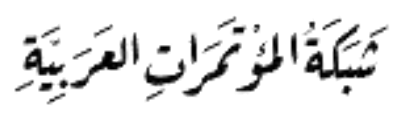

http://arab.kmshare.net/

Available online at http://proceedings.sriweb.org

$\mathrm{C}$

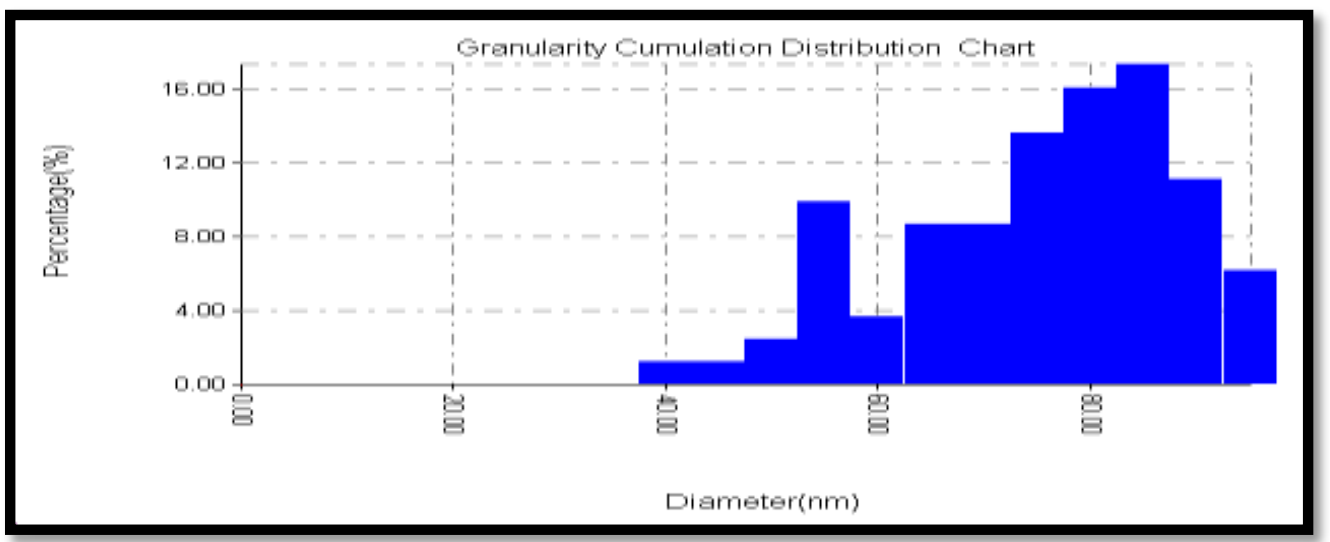

Figure 2: $\mathrm{AFM}$ image of $\mathrm{AuNP}_{\mathrm{S}}$ synthesized by using gel as reducing agent (A) 2D, (B) 3D, (C) average diameter $(70 \mathrm{~nm})$

\section{Transmission Electron Microscopy (TEM):}

TEM is the one of the most popular techniques for the characterization of nanoparticles. In this technique, a real image of nanoparticles is taken with different magnifications to develop a more detailed or general shape of nanoparticles .(22)The TEM images (Figure 3) show the AuNPs in variable shapes. The size of the particles ranged from $14-25 \mathrm{~nm}$.
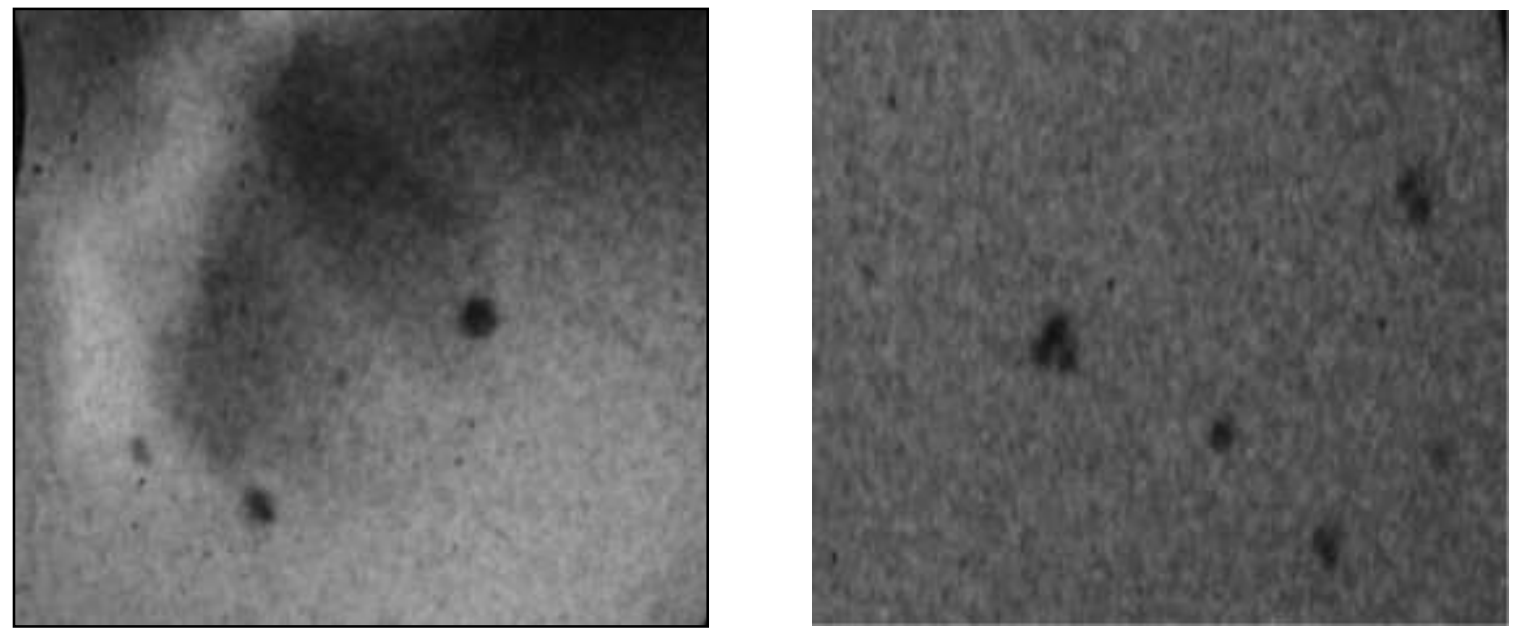


\section{Global Proceedings Repository \\ American Research Foundation}

ISSN 2476-017X

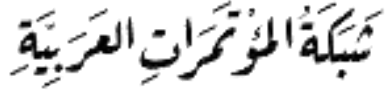

http://arab.kmshare.net/

Available online at http://proceedings.sriweb.org

Figure 3: TEM image shows particles size of the synthesized AuNPs at $14 \mathrm{~nm}$ and $25 \mathrm{~nm}$

\section{DPPH radical scavenging activity of AuNPs:}

In vitro antioxidant activity of AuNPs was investigated by DPPH assay.A series of AuNPs concentrations added to the water samples in order to evaluate the capacity of AuNPs to inhibit the free radical formation which induced by gamma radiation. The results are summarized in Table 1.In its radical form, DPPH absorbs around $526 \mathrm{~nm}$, and its absorbance decreases upon reduction with an antioxidant. Thus, the radical scavenging activity in the presence of antioxidant can be monitored by a decrease in the absorbance of DPPH solution as shown in Figure4.

Absorbance and percent of inhibition for DPPH radical scavenging activity as a function of AuNPs concentration is presented in Figure 5. A perusal of the results shows that at concentration $242.65 \mu \mathrm{g} / \mathrm{ml}$ has maximum percent of inhibition $(63.6 \%)$. The results were agreement with the previous work by Rana M. Yas(23), where the behavior of absorbance and free radicals inhibition is the same.

Table: Values of DPPH absorbance and inhibition \% with AuNPs concentrations.

\begin{tabular}{|c|c|c|}
\hline Water samples & DPPH absorption & Inhibition \% \\
\hline Irradiated water(control) & 0.667 & \\
\hline Au NPs concentration $\mu \mathrm{g} / \mathrm{ml}$ & & 37.6 \\
\hline 53.70 & 0.416 & 43.9 \\
\hline 107.00 & 0.374 & 47.9 \\
\hline 134.30 & 0.347 & 55.3 \\
\hline 159.30 & 0.298 & 58.2 \\
\hline 214.80 & 0.279 & 63.6 \\
\hline 242.65 & 0.243 & \\
\hline
\end{tabular}




\section{Global Proceedings Repository \\ American Research Foundation \\ ISSN 2476-017X

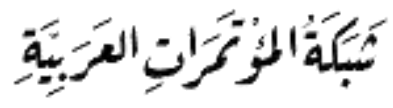 \\ http://arab.kmshare.net/}

Available online at http://proceedings.sriweb.org

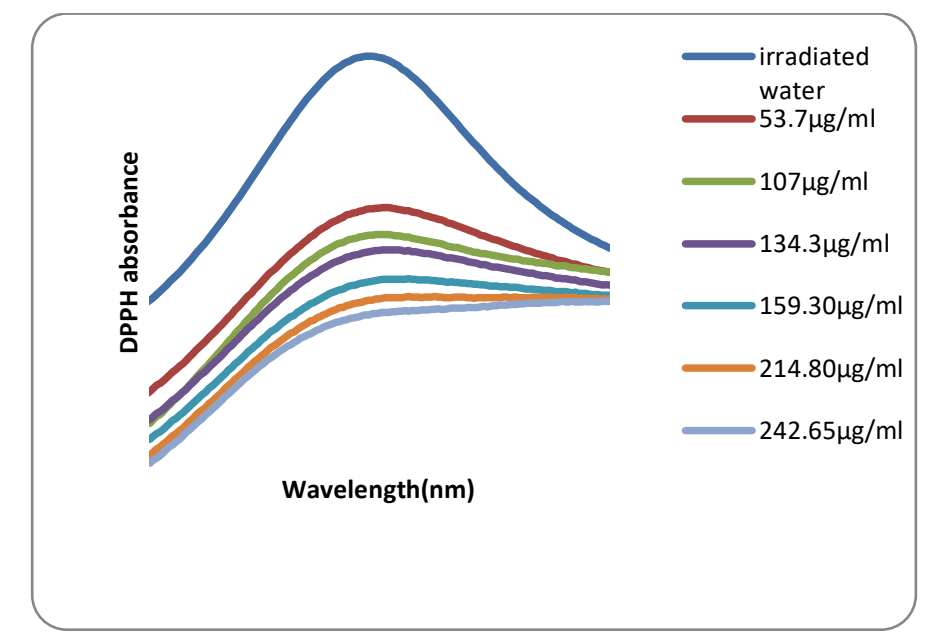

Figure 4: The absorbance of DPPH around $526 \mathrm{~nm}$ with different AuNPs concentrations.

A

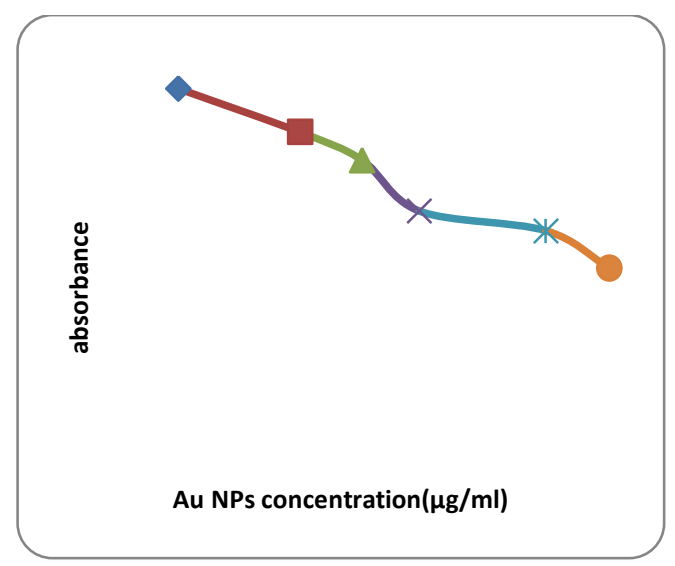




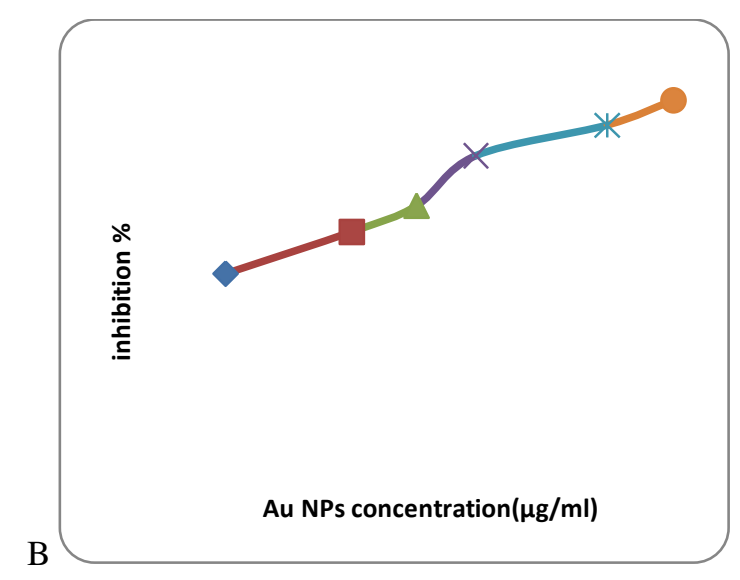

Figure 5: (A) DPPH absorption and(B) free radicals inhibition with differentAuNPs concentrations.

\section{Conclusions:}

This work describes synthesis of gold nanoparticles by a novel chemical route was used by adding the $\mathrm{Au}^{3+}$ solution to the reducing agent with heating and stirring. Stable gold nanoparticles for a longer time were obtained through this easy method. From the results of the experiments, it was concluded that gel reduces $\mathrm{Au}^{+3}$ ion to nanoparticles of gold metal $\left(\mathrm{Au}^{0} \mathrm{NPs}\right)$. It is noted that the same results for both types of laboratory and commercial gel .UV-Vis, zeta potential, AFM and TEM studies were used to characterize the synthesized gold nanoparticles. The UV-Vis spectra showed a maximum absorption at $524 \mathrm{~nm}$. The AFM showed an average size value of $70 \mathrm{~nm}$ diameter, whereas the size values measured by TEM image data were 14 and $25 \mathrm{~nm}$.

The free radical scavenging property as measured by DPPH method showed that percentage of inhibition increases with increasing concentrations of synthesized gold nanoparticles. Thus the synthesized AuNPs could play the role of a neoadjuvant antioxidant offering effective protection from free radicals in a wide range of conditions. Therefore the antioxidant behavior of AuNPs makes them useful in therapy of many diseases caused by oxidative stress.

\section{References:}

[1] P. Pimpang, W. Sutham, N. Mangkornton, P. Mangkorntong, S. Choopun(2008) "Effect of Stabilizer on Preparation of Silver and Gold Nanoparticle UsingGrinding Method" Chiang Mai J. Sci. 35(1): 250-257. 


\section{Global Proceedings Repository \\ American Research Foundation}

ISSN 2476-017X

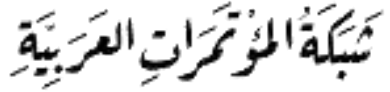

http://arab.kmshare.net/

Available online at http://proceedings.sriweb.org

[2] K. L. Kelly, E. Coronado, L .L . Zhao, G. C. Schatz (2003) "The Optical Properties ofMetal Nanoparticles: The Influence of Size, Shape, and Dielectric Environment" J. Phys. Chem. 107(3):668-677.

[3] J. Turkevich, P. C. Stevenson, J. Hillier (1951) "A study of the nucleation and growth processes in the synthesis of colloidal gold" Discuss. Faraday. Soc. 11: 55-75.

[4] Ornanong S, Kittipongpatana, Burapadaja S, and Kittipongpatana, N.,(2009) "CorboxymethylMungbean Starch as a New Pharmaceutical Gelling Agent for Topical Preparation", Drug Development and Industrial Pharmacy, Informa Healthcare,35 :34-42.

[5] Mohammed F.A,(2001) "Topical permeation characteristics of diclofenac sodium from NaCMC gels in comparison with conventional gel formulations," Drug Development and Industrial Pharmacy, Vol. 27, 1083-1097.

[6] Fang J.Y, Sung K.C, Lin H.H, Fang C.L.,(2006) "Transdermal iontophoretic delivery of diclofenac sodium from various polymer formulations: in vitro and in vivo studies," International journal of pharmaceutics,11;327(1-2):6-11

[7] M.T. Islam, N. Rodriguez-Hornedo, S. Ciotti and C. Ackermann (2004)"Rheological characterization of topical Carbomer gels neutralized to different PH ". Pharmaceutical Research 21, 1192-1199.

[8] D.D. Desai, J.F. Schmucker and D. Light (2006)CarbopolUltrez 10 polymer: A new universal thickener fort the personal care industry. Noveon, The Lubrizol Corporation,

[9] C W. Liu, M. Hu, W. Liu, C. Xue, H. Xu and X. Yang (2008)"Investigation of thecarbopol gel of solid lipid nanoparticles for the transdermal iontophoretic delivery oftriamcinolone acetonide acetate". International Journal of Pharmaceutics 364, 135-141. levelend.

[10] IAEA 2010, Radiation Biology, A Handbookfor Teachersand Students, Vienna, Printed by the IAEA in Austria.

[11] C. K. K. Nair, D. K. Parida, and T. Nomura(2001) "Radioprotectors in radiotherapy", $J$ Radiat Res. 42, 21-37.

[12] K. H. Cheesman and T. F. Salter 1993 "An introduction to free radicals chemistry", Br Med Bull, 49, 481-493.

[13] M. S. Abdel-Aziz , M. S. Shaheen ,A. A. El-Nekeety and M. A. Abdel-Wahhab2014" Antioxidant and antibacterial activity of silver nanoparticles biosynthesized using Chenopodiummurale leaf extract" , J SauChem Soc., 18: 356-363..

[14] S. Arun, U. Saraswathi and Singaravelu2015" Investigation on the free radical scavenging activity of biogenic silver nanoparticle", Int J PharmBio Sci, 6(2), 439 - 445.

[15] P. Prema, S .Thangapandiyan 2013 " In-vitro antibacterial activity of gold nanoparticles capped with polysaccharide stabilizing agents", Int J Pharm Pharm Sci. 5, 310-314. 


\section{Global Proceedings Repository \\ American Research Foundation}

ISSN 2476-017X

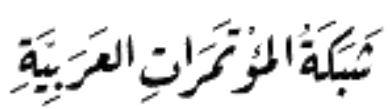

http://arab.kmshare.net/

Available online at http://proceedings.sriweb.org

[16] D. Pissuwan, C. H. Cortie, S. M.Valenzuela, M. B.Cortie, 2010" Functionalised gold nanoparticles for controlling pathogenic bacteria", Trends Biotechnol.28, 207.

[17] Eugenio José Garcia, TatianeLuizaCadorinOldoni, SeverinoMatias de Alencar, Alessandra Reis, Alessandro D. Loguercio, Rosa Helena Miranda Grande,2012 " Antioxidant activity by DPPH assay of potential solutions to be applied on bleached teeth", Braz Dent J, 23,1, 22-27.

[18] C. Dipankar, S. Murugan, 2012 " The green synthesis, characterization and evaluation of the biological activities of silver nanoparticles synthesized from Iresineherbstii leaf aqueous extracts", Colloids Surf B, 98:112-119.

[19] A. Choudhury, A. Malhotra, P. Bhattacharjee, G. S. Prasad (2014) "Facile and rapid thermo- regulated biomineralization of gold by pullulan and study of its thermodynamic parameters" Carbohydrate Polymers. 106(5) : 154-159.

[20] V. Raj, K. Sreenivasan(2010) "Selective detection and estimation of C-reactive protein in serum using surface - functionalized gold nano - particles"Anal. Chim. Acta,662(2):186192.

[21] J. Vasenka, S. Manne, R. Giberson, T. Marsh, E. Henderson(1993) "Colloidal Gold Particles as an Incompressible AFM ImagingStandard for Assessing the Compressibility of Biomolecules"Biophys J. 65: 992-997.

[22] Z. Wang, M. Mohamed, S. Link, M. El-Sayed(1999)"Crystallographic facets and shapes of gold nanorods of different aspect ratios" Surf. Sci. 440(1): 809- 814.

[23] R. M. Yas, (2016) " Study of Nanoparticles as Free Radicals Scavengers for Protection from Radiation Hazard", PhD. Thesis, University of Baghdad, Baghdad, Iraq.

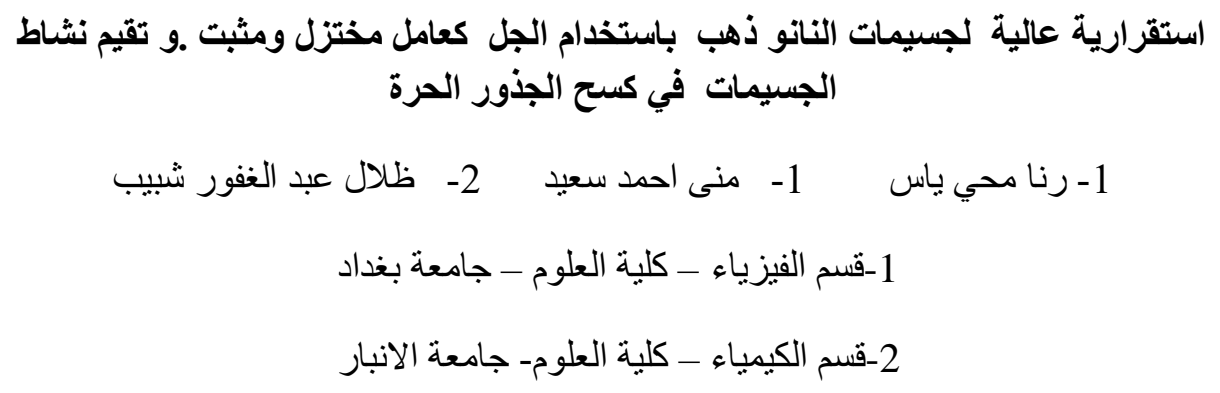

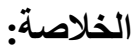




\section{Global Proceedings Repository \\ American Research Foundation}

ISSN 2476-017X

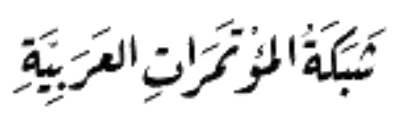

http://arab.kmshare.net/

Available online at http://proceedings.sriweb.org

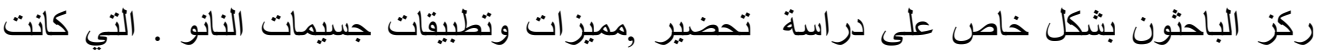

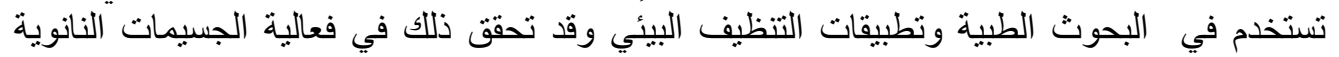

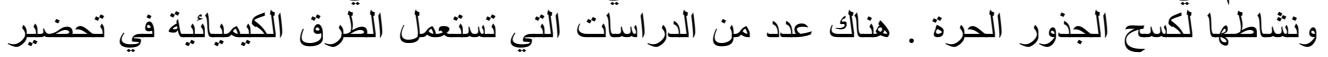

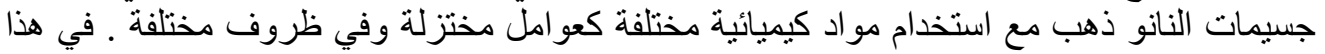

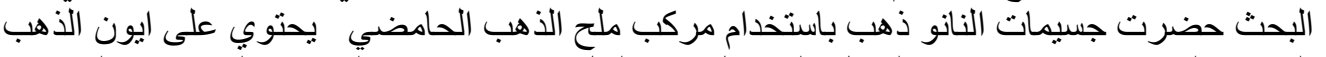

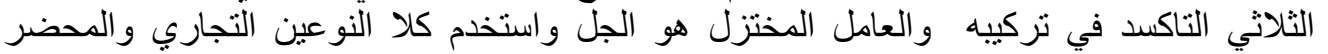

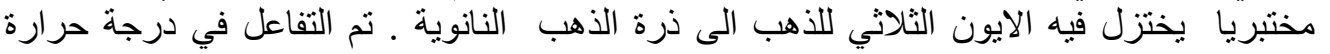

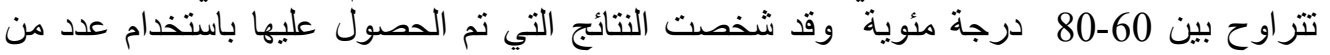

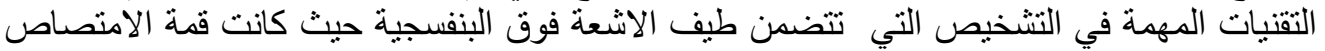

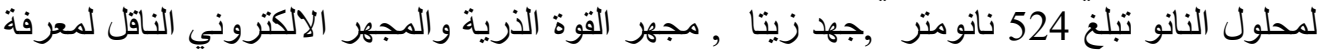

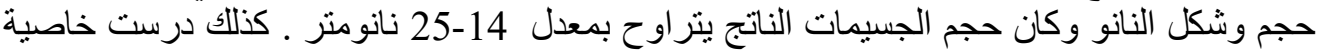

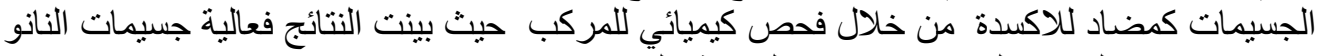
ذهب في كسح الجذور الحرة والاضرار المؤذية التي تسبيها.

الكلمات المفتاحية : جسيمات النانو ذهب , الجل , الخصائص, التحضير, الاستقرارية , مختبريا, الكسح 